\title{
Survivin and cyclin D1 are jointly expressed in thyroid papillary carcinoma and microcarcinoma
}

\author{
ALFREDO ANTONACI ${ }^{1}$, FABRIZIO CONSORTI ${ }^{1}$, STEFANIA MARDENTE $^{2}$, \\ STEFANIA NATALIZI $^{2}$, GLORIA GIOVANNONE ${ }^{1}$ and CARLO DELLA ROCCA ${ }^{2}$ \\ Departments of ${ }^{1}$ Surgery 'Francesco Durante' and ${ }^{2}$ Experimental Medicine, University 'Sapienza' of Rome, Rome, Italy
}

Received January 9, 2008; Accepted March 17, 2008

\begin{abstract}
In order to define more effective predictive markers for clinical management and prognosis, we evaluated the expression of cyclin D1 and survivin in large papillary thyroid carcinoma (LPTC) and microcarcinoma (PTM). Sixty-seven patients operated for papillary carcinoma (36 of which with PTM) were considered. Immunochemistry for cyclin D1 and survivin was performed in samples from tumor mass and nodal metastases. There were not significant differences between LPTC and PTM as to patients personal data, TNM or MACIS staging, nodal invasion and multifocality, while capsular invasion was significantly more frequent in LPTC. Cyclin D1 and survivin were expressed at a very high rate and almost to the same extent in LPTC and PTM, both in tumoral mass and in nodal metastases. Survivin showed only cytoplasmic expression. Cyclin D1 and survivin over-expression are probably early events in tumorigenesis of thyroid papillary carcinoma but their full role in the process of tumor progression and their clinical value are still to be investigated.
\end{abstract}

\section{Introduction}

A papillary thyroid microcarcinoma (PTM) is defined by WHO as a tumor $\leq 1 \mathrm{~cm}$, but this morphological definition does not cope with a distinct clinical behaviour and an agreed clinical management. Despite the common belief of a low malignancy of PTM, mainly based on the high rates of clinically silent microcarcinoma found in autoptic series (1), and the subsequent use of limited surgical excision (2), some authors suggest that the treatment of PTM should not be different from the treatment of patients with conventional thyroid carcinoma (3-7), while others did not find differences independently of the primary treatment (8).

Correspondence to: Dr Fabrizio Consorti, Dip. di Chirurgia 'F. Durante', Viale del Policlinico, I-00161 Roma, Italy

E-mail: fabrizio.consorti@uniroma1.it

Key words: thyroid neoplasm, proto-oncogene, anti-apoptotic protein
In order to define more effective predictive markers for clinical management and prognosis, many researchers focused on biologic and genetic features of thyroid tumors, with the aim of correlating them with aggressiveness and outcome. Some authors have recently associated mutations in genes that control the cell cycle, the cellular proliferation or apoptosis with morphology and prognosis of thyroid cancer. A correlation between over-expression of cell cycle genes Ki67 and clinical parameters, such as age or capsular invasion, has been found in papillary carcinoma (9). Cyclins and their associated cyclin dependent kinases are the central machinery that control cell cycle progression. Up-regulation of the cyclin D1 proto-oncogene has been indicated as a marker predicting an increased risk of metastasis in PTM (10). Increase of cyclin D1 and of the anti-apoptotic protein survivin contributes to cell survival and proliferation in lung cancer cells (11). Moreover, a link has been reported between the expression of survivin and dedifferentiation of thyroid carcinoma (12).

The aim of our study was to evaluate whether cyclin D1 and survivin are expressed in a similar way in PTM and in large papillary thyroid carcinoma (LPTC), if they could be considered as predictive markers of metastases and if their expression is linked to known morphologic features of tumor aggressiveness.

\section{Materials and methods}

We considered 67 patients operated at our Department in the last two years, who had a diagnosis of papillary thyroid carcinoma. Thirty-six of them $(53.7 \%)$ were PTM. There were 30 women and 6 men, with a mean age of $49.9 \pm 11.1$ (range 2-70) years, while the remaining 31 were 24 women and 7 men, with a mean age of $48.0 \pm 14.8$ (range 20-75) years. The size of PTM was from 2 to $10 \mathrm{~mm}$ (mean $6.4 \pm 2.6$ $\mathrm{mm}$ ) while that of LPTC was from 11 to $50 \mathrm{~mm}$ (mean 21.8土11.3 mm).

Patients were staged according to TNM 2002 by UICC and MACIS scoring system (Metastases, Age, Completeness of resection, Invasion, Size) (13). Thirty-four out of 36 patients with PTM had a total thyroidectomy, while 2 underwent lobo-istmectomy, completed to a total thyroidectomy with re-operation after pathological diagnosis. All patients with LPTC underwent total thyroidectomy. All patients $>45$ years or with multifocal PTM underwent I131 radiotherapy and 
suppressive doses of 1-tiroxine were then administered, while the others received only suppressive l-tiroxine.

Immunohistochemistry. Formalin-fixed paraffin-embedded tissue sections $3 \mu \mathrm{m}$ thick were dewaxed in toluene and rehydrated through graded alcohols to water. Endogenous peroxidase activity was blocked with $3 \%$ hydrogen peroxide. Primary monoclonal antibodies for cyclin D1 (Dako Corp. A/S, Gloustrup Denmark, clone DCS-6); pan-cytokeratin (clone C-11 Sigma, Saint Louis, MO, USA); survivin (IgG fraction of antiserum developed in rabbit, Sigma) were used at dilutions respectively of 1:100, 1:800 and 1:500, overnight at room temperature. Slides were then washed in PBS and secondary incubations were carried out using peroxidase conjugated secondary antibodies. Slides were counterstained with hematoxylin and eosin. Negative controls replaced primary antibodies with normal human serum.

Evaluation of immunohistochemical results. Immunoreactivity was independently assessed by two of the authors (S. Natalizi and C. Della Rocca), the results were compared and an agreement was reached on conflicting evaluation. Cyclin D1 and survivin expression was graded on the basis both of the intensity of staining within the tumor cells and the percentage of positive cells within each tumor. Only nuclear staining for cyclin D1 was considered to be a positive expression, while isolated cytoplasmic staining was ignored. Both nuclear and cytoplasmic subcellular localization was instead considered for survivin.

The intensity of nuclear staining was graded from 0 to 3 as it follows: grade 0 , absence of staining; grade 1 , faint staining (requiring high power assessment); grade 2, moderate staining (easily appreciated at low power); and grade 3, intense staining. Grades 2 and 3 were considered as positive. We graded the distribution of positive cells in tumors that stained for cyclin D1 and/or survivin as follows: focal staining in $<10 \%$ of tumor cells; widespread staining in $10-50 \%$ of tumor cells; and grade 3 , diffuse staining in $>50 \%$ of tumor cells.

Statistical analysis. Fisher's exact test and $\chi^{2}$ test were used to evaluate the strength of association between variables, Student's t-test to compare means. Data were stored and analysed by Epi-Info software, by WHO.

\section{Results}

Clinicopathological data. There was not significant difference between PTM and LPTC groups as to patients personal data, TNM or MACIS staging, nodal invasion and multifocality, while capsular invasion was significantly more frequent in LPTC (Table I).

Cyclin D1 and survivin expression. Cyclin D1 and survivin expression were strongly correlated in all patients. We observed a nuclear staining for cyclin D1 with an intensity of grade 2 to grade 3 in all examined LPTCs and in $61.1 \%$ of PTMs (Fig. 1). The number of positive cells ranged from widespread to diffuse in most of the samples. Nodal metastases were always positive in terms of nuclear staining intensity,
Table I. Comparison between personal, clinical and pathological features of papillary thyroid microcarcinoma (PTM) and carcinoma of larger size (LPTC).

\begin{tabular}{|c|c|c|c|}
\hline & PTM & LPTC & \\
\hline No. of cases & 36 & 31 & \\
\hline \multicolumn{4}{|l|}{ Gender } \\
\hline M & 6 & 7 & \\
\hline $\mathrm{F}$ & 30 & 24 & $\mathrm{NS}^{\mathrm{a}}$ \\
\hline \multicolumn{4}{|l|}{ Age } \\
\hline Mean & $49.9 \pm 11.1$ & $48 \pm 14.8$ & $\mathrm{NS}^{\mathrm{b}}$ \\
\hline Range & $29-70$ & $20-75$ & \\
\hline \multicolumn{4}{|l|}{ Size (mm) } \\
\hline Mean & $6.36 \pm 2.6$ & $21.8 \pm 11.3$ & \\
\hline Range & $2-10$ & $11-50$ & \\
\hline \multicolumn{4}{|l|}{ Pathology } \\
\hline Papillary & 25 & 21 & $\mathrm{NS}^{\mathrm{a}}$ \\
\hline Follicular var. & 5 & 9 & \\
\hline Mixed var. & 3 & 1 & \\
\hline Capsulated var. & 2 & & \\
\hline Oxiphyl var. & 1 & & \\
\hline \multicolumn{4}{|l|}{$\begin{array}{l}\text { TNM staging } \\
\text { (UICC 2002) }\end{array}$} \\
\hline I & 31 & 19 & $\mathrm{NS}^{\mathrm{a}}$ \\
\hline II & - & 2 & \\
\hline III & 5 & 9 & \\
\hline IV & - & 1 & \\
\hline \multicolumn{4}{|l|}{$\begin{array}{l}\text { MACIS } \\
\text { classification (13) }\end{array}$} \\
\hline$<6$ & 35 & 4 & $\mathrm{NS}^{\mathrm{a}}$ \\
\hline $6-6.99$ & 1 & 6 & \\
\hline $7-7.99$ & - & 1 & \\
\hline$\geq 8$ & - & - & \\
\hline Capsular invasion & $9(25 \%)$ & $17(54.8 \%)$ & $\mathrm{p}<0.02^{\mathrm{a}}$ \\
\hline $\mathrm{N}^{+}$ & $3(8.3 \%)$ & $6(19.3 \%)$ & $\mathrm{NS}^{\mathrm{a}}$ \\
\hline Multifocality & $\begin{array}{l}9(25 \%), \\
4 \text { bilateral }\end{array}$ & $\begin{array}{c}12(38.7 \%), \\
10 \text { bilateral }\end{array}$ & $\mathrm{NS}^{\mathrm{a}}$ \\
\hline
\end{tabular}

${ }^{\mathrm{a}} \chi^{2}$ test. ${ }^{\mathrm{b}}$ Student's t-test.

but in some cases the number of positive cells was lower than in the primary tumors (Tables II and III, Fig. 2).

Immunoreactivity for cyclin D1 was always related to the neoplastic cells, as was confirmed by the expression of 


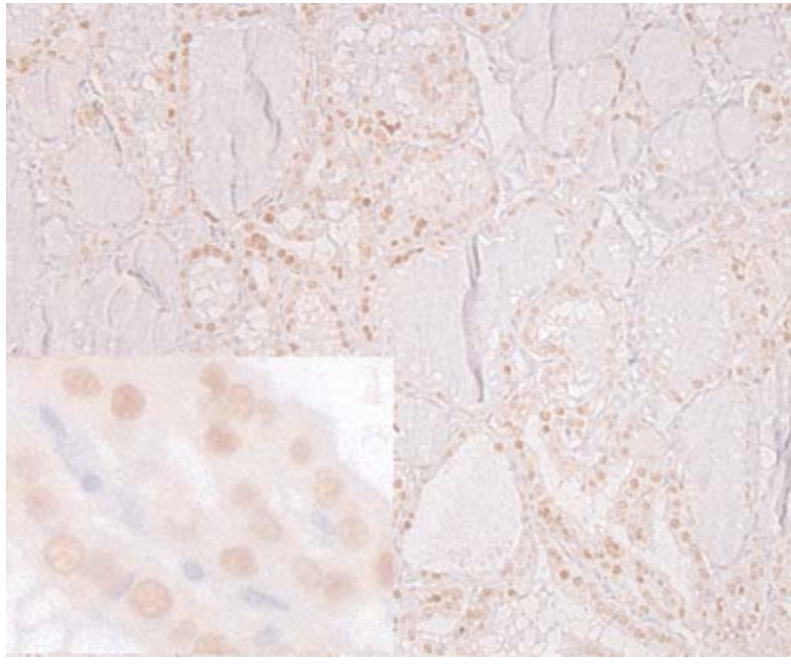

Figure 1. Immunostaining for cyclin D1 of a papillary carcinoma (x10). Insert: magnification $\mathrm{x} 40$ showing nuclear expression.

Table II. Expression of cyclin D1 in papillary thyroid microcarcinoma (PTM), large papillary thyroid carcinoma (LPTC) and nodal metastases. ${ }^{\text {a }}$

\begin{tabular}{lccc}
\hline & $\begin{array}{c}\text { Cyclin D1 } \\
\text { positive (\%) }\end{array}$ & $\begin{array}{c}\text { Cyclin D1 } \\
\text { negative (\%) }\end{array}$ \\
\hline PTM & $22(61.1)$ & $14(39.9)$ \\
LPTC & $31(100)$ & 0 & $(0)$ \\
Nodal metastases from PTM & $3(100)$ & 0 & $(0)$ \\
Nodal metastases from LPTC & $6(100)$ & 0 & $(0)$ \\
\hline
\end{tabular}

${ }^{a}$ Grades 2 (moderate staining easily appreciated at low power) and 3 (intense staining) of intensity were considered positive.

Table III. Number of positive cells for cyclin D1 in papillary thyroid microcarcinoma (PTM), large papillary thyroid carcinoma (LPTC) and nodal metastases.

\begin{tabular}{lccc}
\hline & $\begin{array}{c}\text { Focal } \\
(<10 \%)\end{array}$ & $\begin{array}{c}\text { Wide } \\
(11-50 \%)\end{array}$ & $\begin{array}{c}\text { Diffuse } \\
(>50 \%)\end{array}$ \\
\hline PTM & 0 & 14 & 8 \\
LPTC & 3 & 19 & 9 \\
Nodal metastases from PTM & 0 & 3 & 0 \\
Nodal metastases from LPTC & 0 & 4 & 2 \\
\hline
\end{tabular}

cytokeratin (not shown), that was never seen positive in any of the fibrovascular cells. Normal thyroid follicular cells of the healthy lobe and from the area surrounding the tumor did not express cyclin D1.

Survivin was also positive both in PTM and LPTC, as well as in nodal metastases (Tables IV and V, Figs. 3 and 4). The

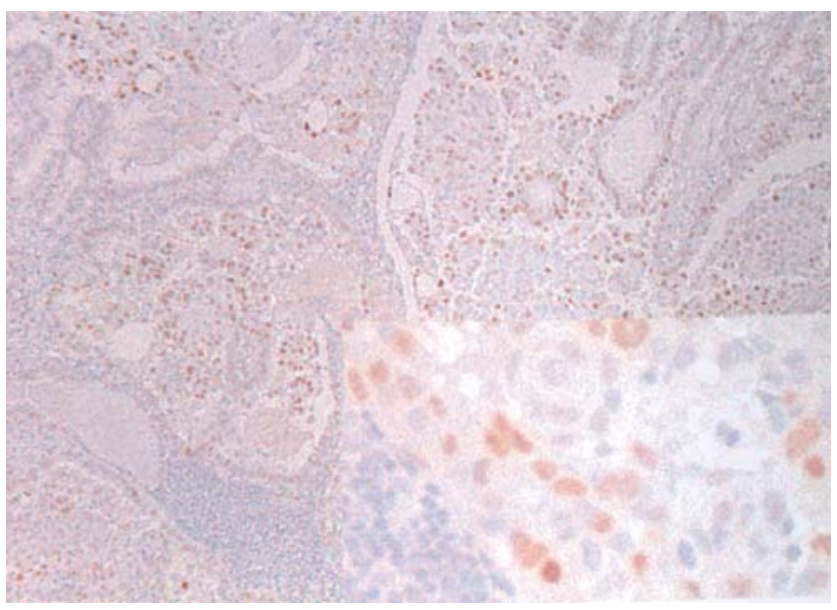

Figure 2. Immunostaining for cyclin D1 of a nodal metastasis (x10). Insert: magnification $\mathrm{x} 40$ showing nuclear expression.

Table IV. Expression of survivin in papillary thyroid microcarcinoma (PTM), large papillary thyroid carcinoma (LPTC) and nodal metastases. ${ }^{a}$

\begin{tabular}{lcrr}
\hline & $\begin{array}{c}\text { Survivin } \\
\text { positive (\%) }\end{array}$ & $\begin{array}{c}\text { Survivin } \\
\text { negative (\%) }\end{array}$ \\
\hline PTM & $24(63.9)$ & $12(36.1)$ \\
LPTC & $29(93.5)$ & 2 & $(6.5)$ \\
Nodal metastases from PTM & $3(100)$ & 0 & $(0)$ \\
Nodal metastases from LPTC & $6(100)$ & 0 & $(0)$ \\
\hline
\end{tabular}

${ }^{a}$ Grades 2 (moderate staining easily appreciated at low power) and 3 (intense staining) of intensity were considered positive.

Table V. Number of positive cells for survivin in papillary thyroid microcarcinoma (PTM), large papillary thyroid carcinoma (LPTC) and nodal metastases.

\begin{tabular}{lccc}
\hline & $\begin{array}{c}\text { Focal } \\
(<10 \%)\end{array}$ & $\begin{array}{c}\text { Wide } \\
(11-50 \%)\end{array}$ & $\begin{array}{c}\text { Diffuse } \\
(>50 \%)\end{array}$ \\
\hline PTM & 0 & 15 & 9 \\
LPTC & 3 & 18 & 8 \\
Nodal metastases from PTM & 0 & 2 & 1 \\
Nodal metastases from LPTC & 0 & 2 & 4 \\
\hline
\end{tabular}

staining was not usually homogeneous but it was more intense in the peripheral part of the tumor and less intense in the cells from the central part of neoplastic mass. Immunoreactivity was concentrated in areas that were positive for cytokeratin, confirming that stromal or blood elements did not express survivin. The positivity was intracellular, almost only cyto-plasmic and often bordering 


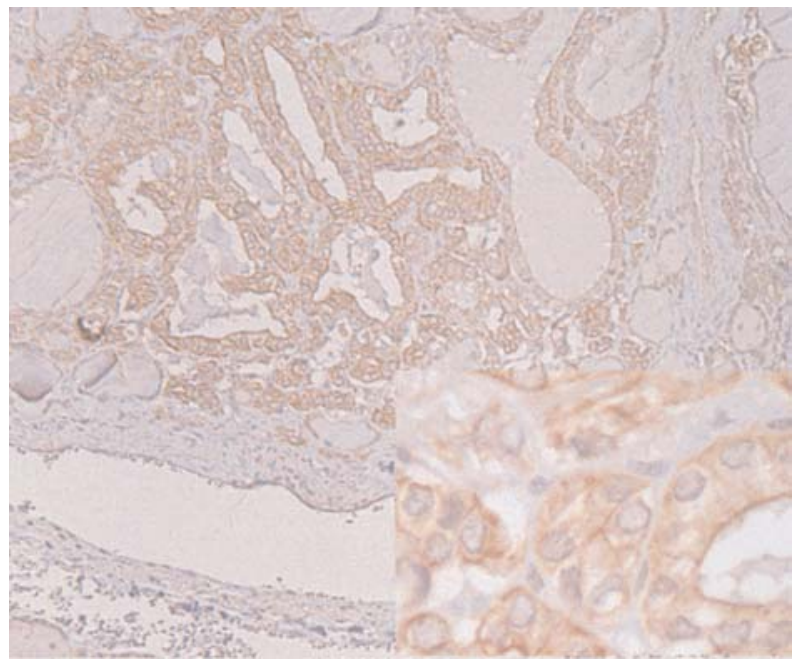

Figure 3. Immunostaining for survivin of a papillary carcinoma (x10). Insert: magnification $\mathrm{x} 40$ showing cytoplasmic expression.

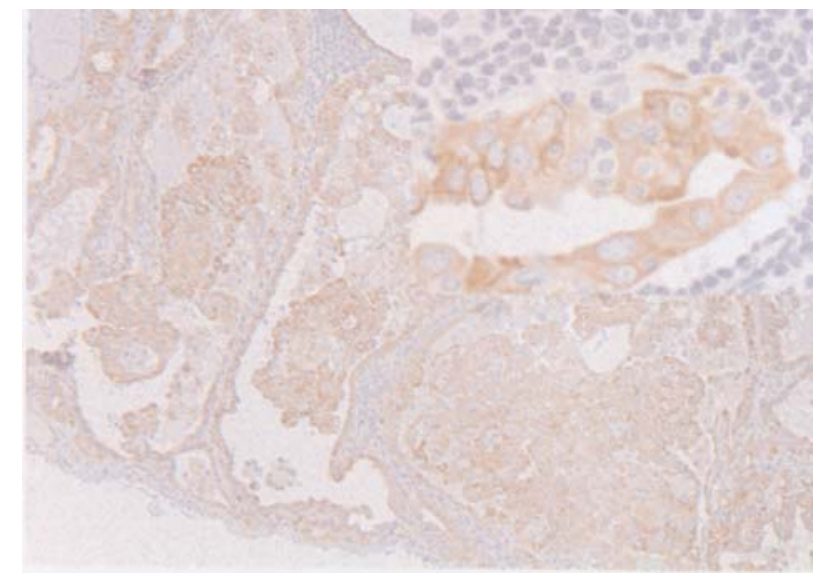

Figure 4. Immunostaining for survivin of a nodal metastasis (x10). Insert: magnification $\mathrm{x} 40$ showing cytoplasmic expression.

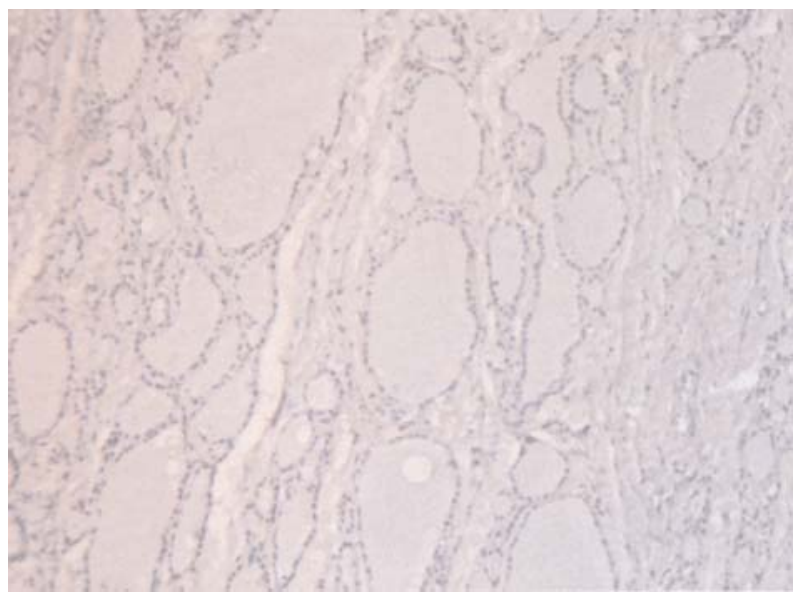

Figure 5. Immunostaining for survivin of a micro-macro follicular hyperplasia without any expression.

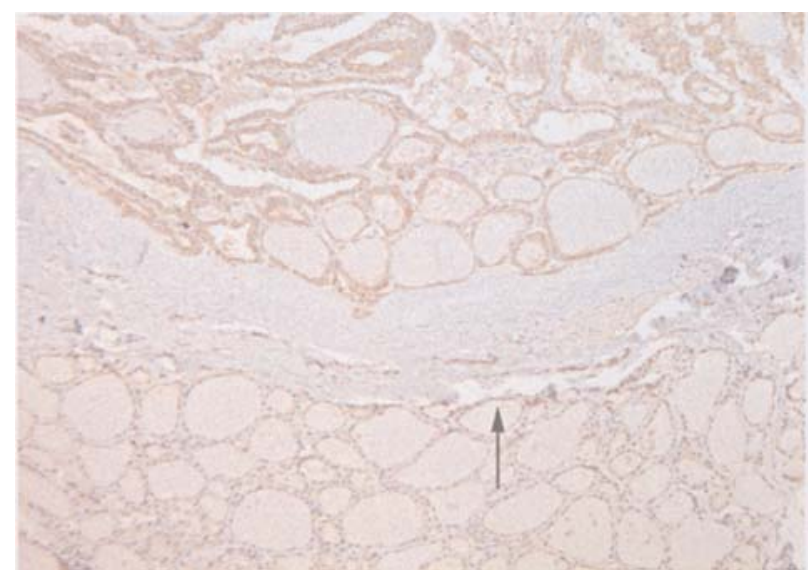

Figure 6. Immunostaining for survivin of a papillary carcinoma (x10). The arrow points at an area surrounding the tumor showing faint positivity.

cellular membrane. Survivin expression was absent in the healthy lobe of the same patient used as a control, and in micro-macro follicular hyperplasia (Fig. 5) while we observed $\leq 20 \%$ of positive cells in peri-tumoral tissues (Fig. 6).

\section{Discussion}

Apart from the obvious disparity in size and capsular infiltration, PTM and LPTC did not show any morphologic difference in our series. Furthermore, about $60 \%$ of PTMs showed the same profile as LPTC regarding the expression of cyclin D1 and survivin. Although PTM is often described as an indolent precursor of larger thyroid cancers, we observed nodal metastases in both PTM and LPTC and metastatic cells from both types of tumors expressed cyclin D1 and survivin.

Cyclin D1 protein over-expression has been already documented in papillary carcinomas suggesting that it could be related with clinical and pathological parameters and that it could constitute a prognostic factor (10). The expression of cyclin D1 in microcarcinomas has also been reported and its over-expression predicts metastatic behaviour (14). We have confirmed that cyclin D1 is expressed in cells from PTM and LPTC and we found that it is over-expressed in nodal metastasis as well. Moreover, we showed that cyclin D1 overexpression is correlated with the expression of survivin.

Survivin is a bifunctional protein that acts as a suppressor of apoptosis and plays also a central role in cell proliferation. It is strongly expressed in many common cancers (15), in follicular thyroid carcinoma (16) and it has been recently linked to the de-differentiation of thyroid carcinoma (12). Ito et al observed mainly nuclear expression of survivin, while in our cases we detected only cytoplasmic staining. It has been suggested (17) that cytoplasmic presence of survivin is related to its anti-apoptotic role and thus to cell survival, while nuclear expression is associated to an increased proliferative activity and possibly to more advanced stages of cancer, even if this assumption is still debated (18). We hypothesize that survivin cytoplasmic expression is associated with early phases of carcinogenesis and its expression in nodal metastases does not necessarily contradict this 
hypothesis. Usually only a small subset of tumor cells accumulates the traits which are needed to produce metastases and the metastatic phenotype is not necessarily related to the size of the primary tumor (19). Papillary thyroid cancers are often characterised by a long indolent course, during which probably various kinds of mutations take place, not necessarily in a mandatory sequence; so we hypothesize that in our cases mutations that are responsible for the metastatic phenotype arose at the same time as those responsible of the survivin and cyclin over-expression. Staining for survivin was more intense in the peripheral part of the tumor and less intense in the cells from the central part of neoplastic mass. This finding could be explained by the fact that cells in the peripheral part of a tumor are those likely to be more active (20). This is compatible with the cancer stem cell theory, in which only the stem cells carry the mutations responsible for survival and progression and they are kept in the more vascular areas of the tumor where more cytokines and growth factors are available. The same mechanism could also explain the faint focal positivity we observed in peritumoral tissues.

In our study survivin also acted as a useful morphologic marker to identify small nodal metastases, even in those patches where cytokeratin positivity was too feeble to be appreciated. Molecular basis of metastasis are poorly understood, researchers have been trying to compare gene expression profiles in primary tumors and metastasis of many human cancers in order to understand why some tumors metastasize early and some others remain clinically silent for years. This latter is often the case in thyroid papillary carcinoma. The study of survivin and its biological roles could contribute to the understanding of thyroid tumorigenesis. Moreover, the higher expression of both cyclin D1 and survivin in tumor tissues than in normal tissue allows to detect single cell transformation and it would be a useful tool in fine needle aspiration samples for an early diagnosis of papillary cancer.

\section{References}

1. Sakorafas GH, Giotakis J and Stafyla V: Papillary thyroid microcarcinoma: a surgical perspective. Cancer Treat Rev 31: 423-438, 2005.

2. Noguchi S, Yamashita H, Murakami N, et al: Small carcinomas of the thyroid. A long term follow up of 867 patients. Arch Surg 131: 187-191, 1996.

3. Chow SM, Law SC, Chan JK, et al: Papillary microcarcinoma of the thyroid-prognostic significance of lymph node metastasis and multifocality. Cancer 98: 31-40, 2003.
4. Baudin E, Travagli JP, Ropers J, et al: Microcarcinoma of the thyroid gland: the Gustave-Roussy Institute experience. Cancer 83: 553-559, 1998.

5. Pearce EN and Braverman LE: Papillary thyroid microcarcinoma outcomes and implications for treatment. J Clin Endocrinol Metab 89: 3710-3712, 2004.

6. Cheema Y, Olson S, Elson D and Chen H: What is the biology and optimal treatment for papillary microcarcinoma of the thyroid? J Surg Res 134: 160-162, 2006.

7. Cappelli C, Castellano M, Braga M, et al: Aggressiveness and outcome of papillary thyroid carcinoma (PTC) versus microcarcinoma (PMC): a mono-institutional experience. J Surg Oncol 95: 555-560, 2007.

8. Appetecchia M, Scarcello G, Pucci E and Procaccini A: Outcome after treatment of papillary thyroid microcarcinoma. J Exp Clin Cancer Res 21: 159-164, 2002.

9. Corapcioglu D, Sak SD, Delibasi T, et al: Papillary microcarcinomas of the thyroid gland and immunohistochemical analysis of expression of $\mathrm{p} 53$ protein in papillary microcarcinomas. J Transl Med 4: 28-32, 2006.

10. Khoo ML, Ezzat S, Freeman JL and Asa SL: Cyclin D1 protein expression predicts metastatic behavior in thyroid papillary microcarcinomas but is not associated with gene amplification. J Clin Endocrinol Metab 87: 1810-1813, 2002.

11. Hung HS, Wu WJ, Cheng YW, et al: Association of cooking oil fumes exposure with lung cancer: involvement of inhibitor of apoptosis proteins in cell survival and proliferation in vitro. Mutat Res 628: 107-116, 2007.

12. Ito Y, Yoshida H, Uruno T, et al: Survivin expression is significantly linked to the dedifferentiation of thyroid carcinoma. Oncol Rep 10: 1337-1340, 2003.

13. Hay ID, Bergstralh EJ, Geollner JR, et al: Predicting outcome in papillary thyroid carcinoma: development of a reliable prognostic scoring system in a cohort of 1779 patients surgically treated at one institution during 1940 through 1989. Surgery 114: 1050-1058, 1989.

14. Lantsov D, Meirmanov S, Nakashima M, et al: Cyclin D1 overexpression in thyroid papillary microcarcinoma: its association with tumor size and aberrant $\beta$-catenin expression. Histopathology 47: 248-256, 2005.

15. Duffy MJ, O'Donovan N, Brennan DJ, et al: Survivin: a promising tumor biomarker. Cancer Lett 249: 49-60, 2007.

16. Haghpanah V, Shooshtarizadeh P, Heshmat R, et al: Immunohistochemical analysis of survivin expression in thyroid follicular adenoma and carcinoma. Appl Immunohistochem Mol Morphol 14: 422-425, 2006.

17. Li F, Yang J, Ramnath N, et al: Nuclear or cytoplasmic expression of survivin: what is the significance? Int $\mathbf{J}$ Cancer 114: 509-512, 2005

18. Stauber RH, Mann W and Knauer SK: Nuclear and cytoplasmic survivin: molecular mechanism, prognostic, and therapeutic potential. Cancer Res 67: 5999-6002, 2007.

19. Loberg RD, Bradley DA, Tomlins S, et al: The lethal phenotype of cancer: the molecular basis of death due to malignancy. CA Cancer J Clin 57: 225-241, 2007.

20. Huang EH, Heidt DG, Li CW and Simeone DM: Cancer stem cells: a new paradigm for understanding tumor progression and therapeutic resistance. Surgery 141: 415-419, 2007. 